\title{
Efeito de Cascas de Café e de Arroz Dispostas nas Camadas do SOlo SObre A GerminaÇÃo E O CRESCIMENTO InICIAL do CARURU-DE-MANCHA ${ }^{1}$
}

\author{
Allelopathic Effect of Coffee and Rice husks arranged in soil layers on the germination and \\ initial growth of Amaranthus viridis
}

\author{
SANTOS, J.C.F. ${ }^{2}$, SOUZA, I.F. ${ }^{3}$, MENDES, A.N.G. ${ }^{3}$, MORAIS, A.R. ${ }^{4}$, CONCEIÇÃO, H.E.O. ${ }^{5} \mathrm{e}$ \\ MARINHO, J.T.S. ${ }^{5}$
}

\begin{abstract}
RESUMO - Estudos dos efeitos dos resíduos de plantas pela utilização de coberturas mortas no controle das plantas daninhas têm apresentado dificuldade de determinar a diferenciação entre alelopatia e competição. Atualmente, muitas pesquisas têm se referido a critérios que propõem evidência à alelopatia. Este trabalho em casa de vegetação visou determinar os efeitos alelopáticos proporcionados pelas cascas de café e de arroz sobre o caruru-de-mancha, por meio das disposições desses resíduos nas camadas do solo. O delineamento experimental foi o de blocos casualizados, com os tratamentos em quatro repetições e organizados num esquema fatorial (3x3), sendo cascas de café e de arroz e vermiculita expandida como um fator e suas disposições, com resíduos depositados no topo, incorporados na superfície e incorporados no fundo, como segundo fator. Como testemunha foi usado um tratamento adicional sem cobertura. De modo geral, resíduos de cascas proporcionaram inibição da germinação e estímulo ao crescimento do caruru-de-mancha. A casca de arroz proporcionou menor índice de velocidade de emergência e germinação de sementes do que a casca de café. A casca de café depositada no topo proporcionou maior crescimento e maior peso da matéria seca do caruru-de-mancha, seguido pela mesma casca incorporada na superfície do solo.
\end{abstract}

Palavras-chave: alelopatia, competição, resíduos, cobertura morta, controle de plantas daninhas.

\begin{abstract}
Studies of plant residue effects involving mulches to control weeds in perennial crops are difficult to carry out due to the need to differentiate between allelopathy and competition. Many researches, nowadays, refer to criteria proving allelopathy. This work was established under greenhouse conditions to determine the allelopathic effects of coffee and rice husks on Amaranthus viridis through their arrangements in soil layers. The experimental design was a randomized block with four replications, arranged in a $3 \times 3$ factorial scheme, with coffee and rice husks and expanded vermiculite being one factor and their residues placed on the top and incorporated into the soil surface and into the bottom, as the other factor. One additional treatment without mulching was used. Overall, plant residues inhibited seed germination and stimulated growth of slender amaranth. Rice husk showed lower emergent velocity index and seed germination than coffee husk. Coffee husk placed on the top provided greater growth and higher dry matter weight of slender amaranth, followed by husk incorporation into the soil surface.
\end{abstract}

Key words: allelopathy, competition, residues, soil mulch, weed control.

1 Recebido para publicação em 15/8/2000 e na forma revisada em 26/1/2001.

Extraído da dissertação apresentada pelo autor à Universidade Federal de Lavras (UFLA), para obtenção do título de Mestre em Agronomia/Fitotecnia.

2 Eng.-Agrônomo, M.S. em Agronomia/Fitotecnia, Pesquisador da EMBRAPA/CPAF-RO. ${ }^{3}$ Eng.-Agrônomo, Doutor, Professor do Departamento de Agricultura - UFLA. ${ }^{4}$ Eng.-Agrônomo, Doutor, Professor do Departamento de Ciências Exatas - UFLA. ${ }^{5}$ Eng.-Agrônomos, Pesquisadores da EMBRAPA. 


\section{INTRODUÇÃO}

No estudo dos efeitos de resíduos vegetais envolvendo coberturas mortas no controle das plantas daninhas, verifica-se que a distinção entre efeito alelopático e efeito competição tem sido difícil, em razão da existência de diversos fatores; conforme Rice (1984), esses dois fenômenos podem ocorrer simultaneamente.

Entende-se por efeito alelopático o processo de adição de substâncias químicas ao meio, provenientes do metabolismo secundário da planta, podendo promover influências detrimentais ou estimulatórias sobre outra; já o efeito competição compreende a subtração por uma planta, em relação a outra, de fatores ligados ao meio ambiente, como água, luz, nutriente, gás carbônico e espaço (Rice, 1984).

Fuerst \& Putnan (1983) relataram que muitos estudos de alelopatia e competição são geralmente considerados de interferência, pelo fato de eles não possuírem referências consistentes ou proposição de critérios de provas.

Durigan \& Almeida (1993) consideraram importante que substâncias alelopáticas atinjam o solo à concentração mínima na qual as plantas são suscetíveis, estando subordinadas à quantidade de aleloquímicos contidos na palha e à velocidade do processo de lixiviação.

A velocidade do processo de lixiviação está relacionada à decomposição dos resíduos, que por sua vez depende de suas propriedades, como rigidez dos tecidos, composição de seus teores e relação $\mathrm{C} / \mathrm{N}$, sofrendo ainda influência das condições ambientais, como temperatura e umidade, e ação dos microrganismos (Almeida, 1991).

Friedman (1995) salienta que resíduos de plantas são freqüentemente deixados no campo como coberturas mortas e que seus efeitos supressivos sobre as plantas daninhas ou culturas são conhecidos. Entretanto, o papel específico de seus aleloquímicos sobre a supressão das plantas ainda não está esclarecido.

Um dos efeitos da utilização de resíduos vegetais como coberturas mortas no controle das plantas daninhas é o alelopático, que pode acontecer no plantio direto de cultivos anuais.
Em culturas perenes, como café, têm-se exemplos de resíduos depositados na lavoura, como a casca de café e casca de arroz, para controlar plantas daninhas, porém necessitando de informações que comprovem sua potencialidade alelopática.

A existência de poucos métodos e a deficiência de um protocolo de pesquisa para determinação da influência química de resíduos vegetais são consideradas fatores limitantes no desenvolvimento dos estudos dessa interferência, requerendo a criação de metodologias novas e complementares que possibilitem o melhor entendimento de utilização da alelopatia e conseqüente incorporação aos processos de pesquisa e produção.

O presente trabalho teve como objetivo determinar o efeito que a casca de café e casca de arroz dispostas no solo produz sobre a germinação e o crescimento inicial do caruru-demancha.

A vermiculita como material inerte, obedecendo aos distintos posicionamentos no substrato, pode ser considerada uma testemunha, no sentido de reforçar a comprovação de liberação de substâncias químicas pelas referidas cascas.

\section{MATERIAL E MÉTODOS}

O experimento foi conduzido no período de novembro a dezembro de 1998, em casa de vegetação localizada na área experimental do Departamento de Agricultura da Universidade Federal de Lavras - UFLA, em Lavras - Minas Gerais.

Foram utilizados vasos para aplicação das coberturas mortas de casca de café, casca de arroz e vermiculita expandida em camadas de $2 \mathrm{~cm}$ de espessura com distintos posicionamentos, tendo mesmo volume e uniformidade, constituindo os tratamentos.

A planta-teste foi o caruru-de-mancha (Amaranthus viridis), que teve suas sementes coletadas numa lavoura experimental de café Catuaí em Lavras-MG, juntamente com o solo para composição do substrato dos vasos, com as características químicas apresentadas na Tabela 1.

Utilizando um termoigrógrafo portátil, ins- 
talado na casa de vegetação, foi possível realizar diariamente as leituras e o registro das temperaturas e umidades do ambiente, durante todo o período de condução do experimento, cujos dados estão consolidados na Tabela 2.

O delineamento experimental empregado foi o de blocos casualizados, com quatro repetições. Os tratamentos foram dispostos num esquema fatorial ( $3 \times 3)$, correspondendo a três tipos de coberturas (casca de café, casca de arroz e vermiculita expandida) e três modos de disposição (depositada no topo, incorporada na superfície e incorporada no fundo), somando-se ainda mais um tratamento adicional sem cobertura morta, considerado testemunha, resultando em 10 tratamentos, num total de 40 parcelas.

Cada parcela correspondeu a um vaso com capacidade para três litros, com diâmetro de boca de $17 \mathrm{~cm}$. Foram plantadas 30 sementes de caruru-de-mancha por vaso; após as avaliações iniciais, procedeu-se ao desbaste, deixando-se apenas cinco plantas.

Na instalação dos tratamentos no substrato dos vasos, aplicou-se a camada de $2 \mathrm{~cm}$ de espessura de cascas ou vermiculita, equivalente ao volume de $450 \mathrm{~mL}$, mantendo-se a mesma medida com uniformidade para todos os materiais nas três disposições citadas. Portanto, os vasos acomodavam cinco medidas ou camadas de $450 \mathrm{~mL}$, sendo uma de resíduo e as outras quatro de solo, conservando sempre uma medida ou camada sobre as sementes, quer seja de solo, resíduo depositado ou resíduo incorporado.

Durante a condução do experimento, foi feito o controle das outras espécies infestantes, pela prática do arranque. Efetuou-se, também, a irrigação dos vasos a cada dois dias, sendo aplicados $100 \mathrm{~mL}$ no topo do vaso e $200 \mathrm{~mL}$
Tabela 2 - Médias semanais de temperaturas e umidades do experimento conduzido em casa de vegetação do Departamento de Agricultura - UFLA, no período de novembro a dezembro de 1998. UFLA. Lavras-MG, 1999

\begin{tabular}{|c|c|c|}
\hline Semanas & $\begin{array}{c}\text { Temperatura } \\
\left({ }^{\circ} \mathrm{C}\right)\end{array}$ & $\begin{array}{c}\text { Umidade } \\
(\%)\end{array}$ \\
\hline 1 & 24,8 & 75,0 \\
2 & 25,2 & 72,0 \\
3 & 27,3 & 67,0 \\
4 & 28,0 & 60,0 \\
5 & 28,4 & 69,0 \\
6 & 26,8 & 71,0 \\
\hline Média Geral & 26,7 & 69,0 \\
\hline
\end{tabular}

na parte de baixo, em bandejas-suportes dos vasos.

Após ter sido verificada a estabilidade da germinação das sementes de caruru, o que ocorreu no $23^{\circ}$ dia do plantio, realizou-se o desbaste das plantas, por meio do corte da parte aérea com tesoura, rente ao solo, deixando as citadas cinco plantas por vaso, para serem conduzidas e avaliadas até o final do experimento.

Foi feita a avaliação das seguintes variáveis:

a) Velocidade de emergência: diariamente, fezse a contagem de plântulas de caruru que emergiram até o 23 dia do plantio, quando ocorreu a estabilização da germinação. Os dados coletados foram utilizados para o cálculo do índice de velocidade de emergência (IVE), conforme critério adotado por Maguire (1962).

b) Porcentagem de germinação: após a estabilização da germinação do caruru no $23^{\circ}$ dia do plantio, anotou-se a soma de plantas que germinaram. Esta soma, em comparação

Tabela 1 - Resultados da análise química das amostras de solo da área experimental, colhidas na profundidade de 0-20 cm e analisadas no Departamento de Ciência do Solo da UFLA. Lavras-MG, 1999

\begin{tabular}{|c|c|c|c|c|c|c|c|c|c|c|c|c|}
\hline \multirow{2}{*}{$\begin{array}{c}\text { pH água } \\
(1: 2,5)\end{array}$} & \multirow{2}{*}{$\begin{array}{c}\text { M.O. } \\
\left(\text { dag kg }^{-1}\right)\end{array}$} & $P$ & $\mathrm{~K}$ & $\mathrm{Ca}$ & $\mathrm{Mg}$ & $\mathrm{Al}$ & $\mathrm{H}+\mathrm{Al}$ & S.B. & $\mathrm{t}$ & $\mathrm{T}$ & $\mathrm{m}$ & $\mathrm{V}$ \\
\hline & & \multicolumn{2}{|c|}{--- $\mathrm{mg} \mathrm{dm}^{-3}----$} & \multicolumn{7}{|c|}{$\begin{array}{l} \\
\end{array} \mathrm{cmol}_{\mathrm{c}} \mathrm{dm}^{-3}$} & \multicolumn{2}{|c|}{----- \% ---- } \\
\hline 5,8 & 2,48 & 10 & 78 & 2,3 & 1,1 & 0,0 & 2,6 & 3,6 & 3,6 & 6,2 & 0,0 & 58,1 \\
\hline
\end{tabular}


com o número total de sementes plantadas (30 sementes), possibilitou o cálculo da porcentagem de germinação.

c) Altura de planta: nas cinco plantas definitivas por vaso, foram medidas com régua suas alturas, a cada período de cinco dias, totalizando cinco avaliações ao final do experimento, no $20^{\circ}$ dia após o desbaste.

d) Número de folhas: nesses mesmos períodos de avaliações de altura, foi também realizada a contagem do número de folhas emitidas por cada uma das cinco plantas definitivas.

e) Emissão foliar: por meio do número de folhas, calculou-se a taxa de emissão foliar, correspondendo à diferença de folhas entre duas datas de avaliações consecutivas, dividida pelo período, em dias, entre estas avaliações.

f) Sintomas de injúrias: durante a condução do experimento foram realizadas avaliações visuais de injúrias sobre o caruru, com descrição dos sintomas causados pelos diversos tratamentos.

g) Matéria seca: ao final do experimento, no $20^{\circ}$ dia após a realização do desbaste, foi feito o corte da parte aérea das plantas rente ao solo. Separaram-se folhas dos caules, ramos, pecíolos, inflorescências e sistema radicular. O material foi acondicionado em sacos de papel e colocado para secar por sete dias, em estufa elétrica com circulação forçada de ar e temperatura ajustável para $40{ }^{\circ} \mathrm{C}$, até atingir peso constante.

h) Área foliar: o índice de área foliar do caruru foi calculado (em $\mathrm{cm}^{2} / 100$ plantas) no final do experimento, pela aplicação do método do disco foliar adaptado por Benincasa (1988). Utilizou-se o alicate de extração de disco foliar com diâmetro-padrão de $1 \mathrm{~cm}$ para coleta de quatro amostras, contendo cada uma cinco discos foliares com áreas e pesos secos conhecidos, possibilitando, conforme respectivos pesos da matéria seca da folha, o cálculo de sua área foliar.

A análise de variância foi realizada de acordo com o modelo apropriado para os experimentos, em esquema fatorial com tratamento adicional, conforme Gomes (1990); quando houve efeito significativo dos tratamentos, foram feitas as comparações de médias com

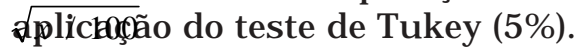

$$
\sqrt{x+1}
$$

Os dados referentes à porcentagem de germinação foram transformados para Arc sen , e aqueles envolvendo a contagem de folhas foram convertidos para

\section{RESULTADOS E DISCUSSÃO}

Inicialmente foi observado que o tipo de cobertura, suas disposições no vaso e suas interações tiveram influências determinantes na velocidade de emergência e porcentagem de germinação das sementes de caruru-de-mancha.

Os valores apresentados pela testemunha (sem cobertura), em relação aos demais trata-

Tabela 3 - Médias de índice de velocidade de emergência e porcentagem de germinação do caruru-de-mancha no $23^{\circ}$ dia do plantio, correspondentes à aplicação dos tratamentos das coberturas mortas de casca de café (CC), casca de arroz (CA) e vermiculita expandida (VE), nas posições depositada no topo (DT), incorporada na superfície (IS) e incorporada do fundo (IF), comparadas com as testemunhas sem cobertura (SC), num experimento em casa de vegetação. UFLA, Lavras-MG, 1999

\begin{tabular}{|c|c|c|c|}
\hline Cobertura & Posição & $\begin{array}{c}\text { Índice de velocidade de } \\
\text { emergência }\end{array}$ & $\begin{array}{c}\text { Porcentagem de } \\
\text { germinação }\end{array}$ \\
\hline \multirow{3}{*}{ CC } & DT & $6,07^{\mathrm{a}}$ & $79 \mathrm{a}$ \\
& IS & $5,21 \mathrm{ab}$ & $49 \mathrm{~b}$ \\
& IF & $4,22 \mathrm{~b}$ & $63 \mathrm{ab}$ \\
\hline \multirow{3}{*}{ CA } & DT & $3,61 \mathrm{a}$ & $61 \mathrm{a}$ \\
& IS & $2,28 \mathrm{a}$ & $36 \mathrm{~b}$ \\
& IF & $2,63 \mathrm{a}$ & $41 \mathrm{ab}$ \\
\hline \multirow{3}{*}{ VE } & DT & $2,93 \mathrm{~b}$ & $43 \mathrm{a}$ \\
& IS & $4,63 \mathrm{a}$ & $60 \mathrm{a}$ \\
& IF & $3,11 \mathrm{~b}$ & $47 \mathrm{a}$ \\
\hline SC & & 5,50 & 90 \\
\hline
\end{tabular}

- Médias seguidas das mesmas letras, dentro da mesma coluna (por cobertura), não diferem entre si pelo teste de Tukey a 5\% de probabilidade.

mentos, mostraram-se superiores a todos os fatores, exceto apenas para a casca de café depositada no topo, que proporcionou índice de velocidade de emergência $10 \%$ maior que o da testemunha (Tabela 3).

Sabe-se que as coberturas mortas podem impedir a passagem da radiação solar, inibindo a germinação e, conseqüentemente, reduzindo o índice de infestação das plantas daninhas (Fleck \& Vidal, 1993). Com base nisso, é razoá- 
vel que as coberturas de resíduo e inclusive a vermiculita composta por material inerte tenham apresentado no geral os menores índices de velocidade de emergência e de porcentagem de germinação, quando comparadas com a testemunha sem cobertura.

No entanto, a apresentação de valores diferenciados do índice de velocidade de emergência e da porcentagem de germinação do carurude-mancha referente ao tratamento com vermiculita, por sua vez em comparação com os dados das coberturas com cascas e entre as próprias cascas, leva à suposição da existência de lixiviação de substâncias alelopáticas por parte destas últimas coberturas, decorrentes do processo de degradação, influenciado pelo posicionamento desses resíduos no substrato.

Um aspecto a ser considerado é que a cobertura morta comporta-se como uma camada isolante, que se interpõe entre a atmosfera e o solo, interceptando os raios solares, reduzindo a temperatura do solo e mantendo seu teor de umidade. Têm-se, portanto, a luz, a temperatura e a umidade como fatores essenciais na quebra de dormência das sementes (Almeida, 1991).

Trabalho de pesquisa sobre a influência da fitocromo na germinação de sementes de Amaranthus revelou que vários fatores ambientais podem regular sua germinação. Embora a luz seja necessária para germinação de algumas sementes, esta necessidade muitas vezes pode ser superada pela temperatura elevada e variar com a flutuação sazonal de dormência da semente. O fato de a variação na sensibilidade de germinação pela luz poder explicar o porquê dos esforços em reduzir a emergência de plantas daninhas pelo cultivo sem luz não é suficiente para produzir resultados consistentes (Gallagher \& Cardina, 1998).

A medição de passagem de luz através das coberturas e a condução do tratamento adicional com ausência total de luz no atual experimento seriam de grande importância caso fossem realizadas, porém somente a influência do isolamento deste fator não seria suficiente para se ter uma distinção do efeito competição das coberturas na germinação.

Gomide (1993), utilizando um tratamento composto com água e ausência de luz para comparação com tratamentos com palha triturada, extrato aquoso e somente com água, veri- ficou que espécies infestantes em estudo não tiveram a emergência de seus propágulos afetada pelo tratamento com ausência de luz.

Vale salientar que, mesmo o plantio das sementes de caruru obedecendo a profundidades iguais para todos os tratamentos, foram registrados dados diferenciados do seu índice de velocidade de emergência e da sua porcentagem de germinação, principalmente quando se relaciona a testemunha sem cobertura com os tratamentos que possuem os resíduos incorporados no fundo, cuja camada superficial acima das sementes é constituída apenas por solo.

$\mathrm{Na}$ apresentação geral das médias dos índices de velocidade de emergência e das porcentagens de germinação do caruru, sob efeito do fator disposição das coberturas mortas no substrato, observou-se que os resíduos vegetais exerceram maior influência para diminuição desses valores, principalmente quando estão posicionados com incorporação na superfície e incorporação no fundo, ocorrendo o contrário com os dados da cobertura de vermiculita.

A obtenção desses resultados combina com as observações constatadas por Patrick (1971) num trabalho sobre decomposição de resíduos culturais, cuja liberação de fitotoxinas evidenciou-se com maior expressão na fase inicial de sua decomposição, e estes resíduos triturados e incorporados no solo apresentaram maior liberação de aleloquímicos após três semanas do início de sua decomposição, havendo diminuição desse processo até a sétima semana.

Convém salientar que o efeito alelopático e sua duração, resultante da incorporação de resíduos, depende da espécie fornecedora, da idade do resíduo, das condições climáticas, das características do solo, da população de microrganismos e da planta receptora (Rice, 1984).

Dentre as coberturas de resíduos vegetais, a casca de arroz apresentou menores indices de velocidade de emergência e porcentagem de germinação do caruru, em comparação aos correspondentes tratamentos com casca de café (Figuras 1 e 2).

A casca de arroz proporcionou média geral de 44 e $27 \%$ a menos do que a da casca de café 
nas três disposições, respectivamente para velocidade de emergência e porcentagem de germinação, sendo $48 \%$ a menos quando comparada à testemunha sem cobertura nas duas variáveis (Tabela 3).

A casca de arroz incorporada na superfície registrou os menores índices do ensaio, com 56 e $26 \%$ a menos do que a casca de café também incorporada na superfície, respectivamente para velocidade de emergência e porcentagem de germinação, sendo ainda 58 e 60\% a menos quando comparada à testemunha sem cobertura, respectivamente para as duas variáveis (Tabela 3).

Estudos realizados por Fujii (1993) revelaram que diferenças significativas no efeito alelopático foram observadas entre diferentes variedades de arroz, em que cultivares melhorados do tipo japonês apresentaram pouca atividade alelopática, enquanto algumas variedades nativas deste mesmo arroz e do arroz vermelho apresentaram forte atividade inibitória.

Tamak et al. (1994b), trabalhando com extratos aquosos de resíduos de arroz sobre culturas, verificaram que concentrações de 5 e $10 \%$ inibiram significativamente a germinação de sementes de trigo, aveia, trevo e lentilha, e a alta concentração de extrato de restolho mais palha de arroz causa completa inibição na germinação de sementes de lentilha. Ainda

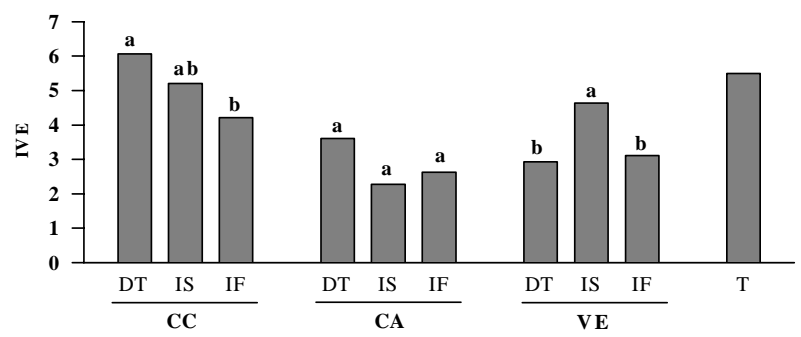

- Médias seguidas das mesmas letras, dentro de cada cobertura, não diferem entre si pelo teste de Tukey a $5 \%$ de probabilidade.

Figura 1 - Índice de velocidade de emergência (IVE) do caruru-de-mancha, no $23^{\circ}$ dia do plantio, correspondente à aplicação dos tratamentos, em função dos tipos de coberturas mortas de casca de café (CC), casca de arroz (CA) e vermiculita expandida (VE), nas posições depositada no topo (DT), incorporada na superfície (IS) e incorporada no fundo (IF), e da testemunha sem cobertura (T), num experimento em casa de vegetação. UFLA, Lavras-MG, 1999.

Planta Daninha, Viçosa-MG, v.19, n.2, p.197-207, 2001 em outro ensaio, Tamak et al. (1994a), utilizando os mesmos extratos, observaram inibição significativa na germinação de sementes de espécies infestantes.

Esses resultados têm semelhança com os obtidos por Araújo et al. (1993), quando estudaram o efeito de diversas coberturas mortas do solo na cultura do alho, em que tratamentos com coberturas de origem vegetal apresentaram número reduzido de plantas daninhas, destacando-se a palha de arroz, com menor índice de infestação.

A decomposição de material vegetal varia de acordo com a qualidade dos tecidos, o tipo de solo e as condições climáticas, com as substâncias liberadas pelos resíduos incorporados ficando diluídas no volume de solo da profundidade de incorporação, enquanto as coberturas depositadas no topo concentram-se na camada superficial. Resíduos secos de materiais maduros, como restos de colheitas, originam fitotoxicidade severa e duradoura, principalmente em baixa temperatura, ocorrendo o contrário com material fresco, ou verde, incorporado (Almeida, 1988).

Pode-se visualizar, neste trabalho, que resíduos incorporados na superfície possibilitaram tendências de menores índices de velocidade de emergência e porcentagem de germinação, com destaque para casca de arroz. Isto pode ser atribuído a supostas influências alelopá-

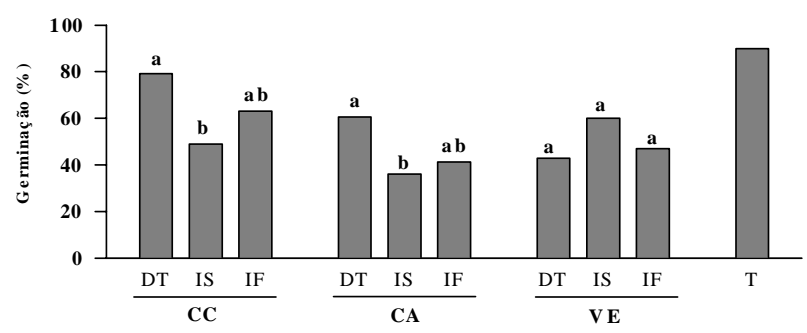

- Médias seguidas das mesmas letras, dentro de cada cobertura, não diferem entre si pelo teste de Tukey a $5 \%$ de probabilidade.

Figura 2 - Porcentagem de germinação (\%) do caruru-demancha, no $23^{\circ}$ dia do plantio, correspondente à aplicação dos tratamentos, em função dos tipos de coberturas mortas de casca de café (CC), casca de arroz (CA) e vermiculita expandida (VE), nas posições depositada no topo (DT), incorporada na superfície (IS) e incorporada no fundo (IF), e da testemunha sem cobertura (T), num experimento em casa de vegetação. UFLA, Lavras-MG, 1999. 
ticas exercidas por esses resíduos vegetais, principalmente casca de arroz, devido à constituição de tecidos resistentes, degradação mais lenta, composição química de seus lixiviados, com maior predominância de ácidos fenólicos, compostos menos degradáveis e de alta eficiência alelopática (Chandramohan et al., 1973, e Chou \& Lin, 1976, citados por Almeida, 1988).

Com relação à variável altura de plantas de caruru-de-mancha, observou-se que as coberturas mortas, os modos de disposição e suas interações, bem como a interação testemunha e demais fatores, tiveram influência determinante na altura da planta-teste caruru.

Pela Tabela 4 , verifica-se que os valores das médias das alturas de plantas para a testemunha sem cobertura foram inferiores aos demais tratamentos com cascas e, em alguns casos, ao tratamento com vermiculita.

Pode-se observar que as coberturas de resíduos vegetais proporcionaram maior incremento nas alturas de plantas do caruru em relação aos demais tratamentos, com destaque

Tabela 4 - Médias de alturas de plantas de caruru-de-mancha, avaliadas aos $23,28,33,38$ e 43 dias do plantio, correspondentes à aplicação dos tratamentos das coberturas mortas de casca de café (CC), casca de arroz (CA) e vermiculita expandida (VE), nas posições depositada no topo (DT), incorporada na superfície (IS) e incorporada no fundo (IF), comparadas com as da testemunha sem cobertura (SC), num experimento em casa de vegetação. UFLA, Lavras-MG, 1999

\begin{tabular}{|c|c|c|c|c|c|c|}
\hline \multirow{2}{*}{ Cobertura } & \multirow{2}{*}{ Posição } & \multicolumn{5}{|c|}{ Períodos de avaliações (Dias) } \\
\cline { 3 - 7 } & & 23 & 28 & 33 & 38 & 43 \\
\hline \multirow{3}{*}{ CC } & DT & $4,34 \mathrm{a}$ & $5,55 \mathrm{a}$ & $7,62 \mathrm{a}$ & $10,08 \mathrm{a}$ & $12,15 \mathrm{a}$ \\
& IS & $2,68 \mathrm{~b}$ & $3,48 \mathrm{~b}$ & $4,99 \mathrm{~b}$ & $6,25 \mathrm{~b}$ & $7,34 \mathrm{~b}$ \\
& IF & $2,19 \mathrm{~b}$ & $2,75 \mathrm{~b}$ & $3,93 \mathrm{~b}$ & $4,88 \mathrm{~b}$ & $5,52 \mathrm{~b}$ \\
\hline \multirow{3}{*}{ CA } & DT & $3,28 \mathrm{a}$ & $4,24 \mathrm{a}$ & $5,64 \mathrm{a}$ & $6,43 \mathrm{a}$ & $7,25 \mathrm{a}$ \\
& IS & $2,51 \mathrm{a}$ & $3,30 \mathrm{a}$ & $4,89 \mathrm{a}$ & $5,92 \mathrm{a}$ & $6,72 \mathrm{a}$ \\
& IF & $2,57 \mathrm{a}$ & $3,20 \mathrm{a}$ & $4,73 \mathrm{a}$ & $5,47 \mathrm{a}$ & $6,23 \mathrm{a}$ \\
\hline \multirow{3}{*}{ VE } & DT & $1,99 \mathrm{a}$ & $2,64 \mathrm{a}$ & $3,80 \mathrm{a}$ & $4,53 \mathrm{a}$ & $5,56 \mathrm{a}$ \\
& IS & $1,67 \mathrm{a}$ & $1,97 \mathrm{a}$ & $2,67 \mathrm{ab}$ & $2,93 \mathrm{ab}$ & $3,23 \mathrm{~b}$ \\
& IF & $1,58 \mathrm{a}$ & $1,85 \mathrm{a}$ & $2,21 \mathrm{~b}$ & $2,41 \mathrm{~b}$ & $2,59 \mathrm{~b}$ \\
\hline SC & & 1,94 & 2,19 & 2,33 & 2,48 & 2,56 \\
\hline
\end{tabular}

- Médias seguidas das mesmas letras, dentro da mesma coluna (por cobertura), não diferem entre si pelo teste de Tukey a 5\% de probabilidade. para a casca de café depositada no topo, que apresentou os maiores valores (Figura 3).

Verificou-se que a casca de café continuou estimulando o crescimento do caruru nas três formas de disposição no substrato até no $43^{\circ}$ dia do plantio. No entanto, a casca de café depositada no topo, seguida da incorporada na superfície, apresentou maior intensidade ao estímulo do crescimento do caruru.

Esses resultados podem ser atribuídos à existência de determinadas influências alelo-

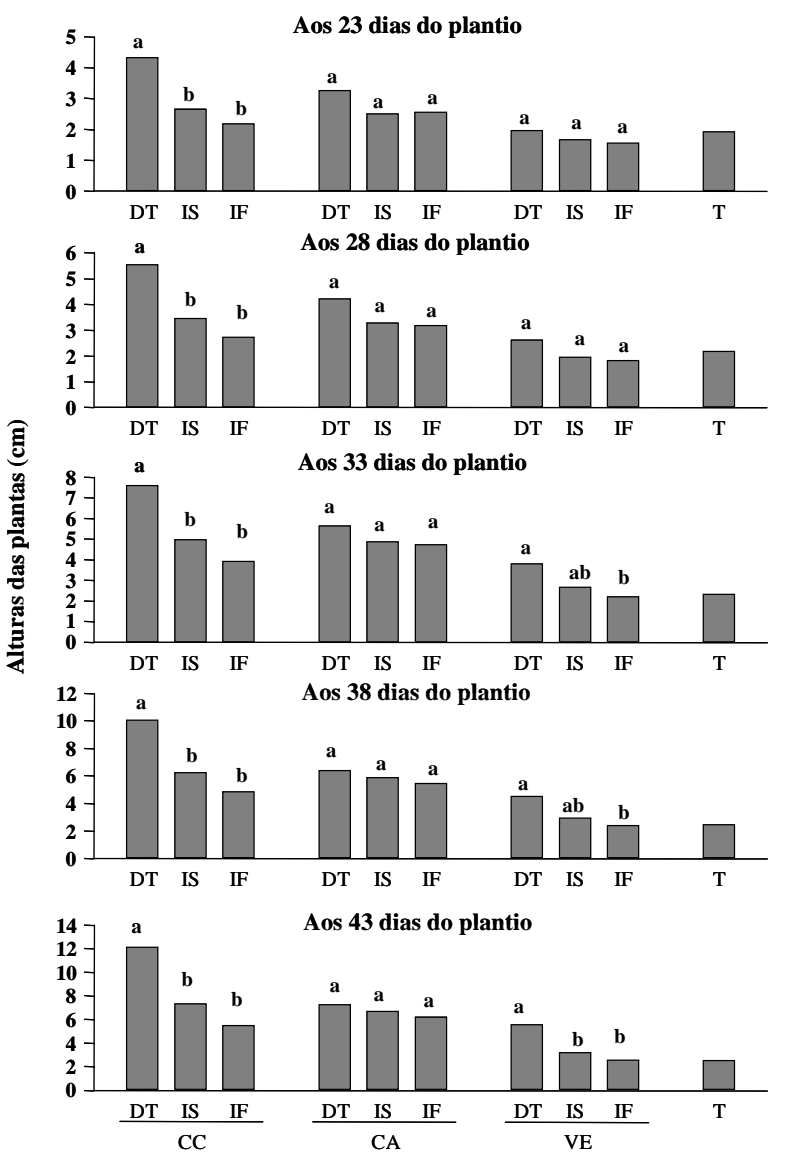

- Médias seguidas das mesmas letras, dentro de cada período (por cobertura), não diferem entre si pelo teste de Tukey a 5\% de probabilidade.

Figura 3 - Altura das plantas de caruru-de-mancha nos cinco períodos de avaliação, aos 23, 28, 33, 38 e 43 dias do plantio, correspondente à aplicação dos tratamentos, em função dos tipos de coberturas mortas de casca de café (CC), casca de arroz (CA) e vermiculita expandida (VE), nas posições depositada no topo (DT), incorporada na superfície (IS) e incorporada no fundo (IF), comparadas com a da testemunha sem cobertura (T), num experimento em casa de vegetação. UFLA, Lavras-MG, 1999. 
páticas por parte desses resíduos, como também este efeito pode ter sido provocado por fornecimento de nutrientes. Segundo Tukey Júnior (1969), na inibição química de uma planta sobre outra, nem todas as substâncias liberadas pelas plantas são inibidoras, podendo algumas apresentar efeitos estimuladores, principalmente aquelas que contêm nutrientes minerais, aminoácidos, ácidos orgânicos, carboidratos e reguladores de crescimento.

Com relação à casca de café, acredita-se que o fato de este resíduo proporcionar maior estímulo ao crescimento do caruru deve-se em grande parte à presença de alcalóides na constituição de seus aleloquímicos. Esses alcalóides são compostos cíclicos que contêm nitrogênio em sua cadeia (Almeida, 1988), principalmente o alcalóide cafeína existente na casca de café, cuja molécula possui capacidade de armazenar nitrogênio (Mazzafera et al., 1996).

Quanto ao fato de o resíduo de casca de arroz provocar menor estímulo ao crescimento do caruru, comparada à casca de café, talvez isto se deva à existência de ácidos fenólicos, os quais são responsáveis pela redução de absorção de micro e macronutrientes em diversas espécies e, principalmente, provocam distúrbios nas plantas, afetando hormônios respon-

Tabela 5 - Médias do número de folhas do caruru-de-mancha, avaliadas aos 23, 28, 33, 38 e 43 dias do plantio, correspondentes à aplicação dos tratamentos das coberturas mortas de casca de café (CC), casca de arroz (CA) e vermiculita expandida (VE), nas posições depositada no topo (DT), incorporada no fundo (IF), comparadas com as da testemunha sem cobertura (SC), num experimento em casa de vegetação. UFLA, Lavras-MG, 1999

\begin{tabular}{|c|l|l|l|l|l|l|}
\hline \multirow{2}{*}{ Cobertura } & \multirow{2}{*}{ Posição } & \multicolumn{5}{|c|}{ Períodos de avaliações (Dias) } \\
\cline { 3 - 7 } & & 23 & 28 & 33 & 38 & 43 \\
\hline \multirow{3}{*}{ CC } & DT & $2,8 \mathrm{a}$ & $3,1 \mathrm{a}$ & $3,3 \mathrm{a}$ & $3,5 \mathrm{a}$ & $3,6 \mathrm{a}$ \\
& IS & $2,6 \mathrm{a}$ & $2,8 \mathrm{~b}$ & $3,1 \mathrm{~b}$ & $3,4 \mathrm{a}$ & $3,5 \mathrm{a}$ \\
& IF & $2,5 \mathrm{a}$ & $2,7 \mathrm{c}$ & $2,9 \mathrm{c}$ & $3,1 \mathrm{~b}$ & $3,3 \mathrm{~b}$ \\
\hline \multirow{3}{*}{$\mathrm{CA}$} & DT & $2,7 \mathrm{a}$ & $2,9 \mathrm{a}$ & $3,1 \mathrm{a}$ & $3,2 \mathrm{ab}$ & $3,3 \mathrm{ab}$ \\
& IS & $2,7 \mathrm{a}$ & $2,9 \mathrm{a}$ & $3,1 \mathrm{a}$ & $3,3 \mathrm{a}$ & $3,4 \mathrm{a}$ \\
& IF & $2,6 \mathrm{a}$ & $2,8 \mathrm{a}$ & $3,0 \mathrm{a}$ & $3,1 \mathrm{~b}$ & $3,2 \mathrm{~b}$ \\
\hline \multirow{3}{*}{ VE } & DT & $2,6 \mathrm{a}$ & $2,7 \mathrm{a}$ & $2,9 \mathrm{a}$ & $3,1 \mathrm{a}$ & $3,2 \mathrm{a}$ \\
& IS & $2,4 \mathrm{a}$ & $2,5 \mathrm{~b}$ & $2,7 \mathrm{~b}$ & $2,8 \mathrm{~b}$ & $2,9 \mathrm{~b}$ \\
& IF & $2,3 \mathrm{a}$ & $2,5 \mathrm{~b}$ & $2,5 \mathrm{c}$ & $2,6 \mathrm{c}$ & $2,7 \mathrm{c}$ \\
\hline SC & & 2,2 & 2,4 & 2,5 & 2,5 & 2,6 \\
\hline
\end{tabular}

- Médias seguidas das mesmas letras, dentro da mesma coluna (por cobertura), não diferem entre si pelo teste de Tukey a 5\% de probabilidade. sáveis pelo crescimento, como o ácido giberélico e ácido indolacético (Almeida, 1988).

Camargo et al. (1995), observando os efeitos no rendimento da cultura de arroz irrigado pela incorporação de palha de arroz em um Gleissolo, verificaram que, dada a elevada relação $\mathrm{C} / \mathrm{N}$ desse resíduo, a adição de palha antes da inundação da área pode ter levado à deficiência de nitrogênio, em decorrência da imobilização pela microbiota.

Com base nas médias de folhas emitidas pelo caruru, pode-se observar ligeira tendência de a cobertura morta de casca de café proporcionar maior emissão de folhas do que a cobertura de casca de arroz, inclusive superando os dados do tratamento com vermiculita expandida e a testemunha sem cobertura (Tabela 5).

A cobertura de casca de café depositada no topo proporcionou maior número de folhas, quando comparada a todos os demais tratamentos em todos os períodos de avaliações, combinando com os valores apresentados pelas alturas de plantas do caruru deste mesmo tratamento.

A casca de café apresentou as maiores taxas de emissão foliar, principalmente depositada no topo e incorporada na superfície do substrato, superando todos os demais trata-

Tabela 6 - Médias das taxas de emissão foliar do caruru-demancha, em quatro avaliações, sob influência das coberturas mortas de casca de café (CC), casca de arroz (CA) e vermiculita expandida (VE), nas posições depositada no topo (DT), incorporada na superfície (IS) e incorporada no fundo (IF), comparadas com as da testemunha sem cobertura (SC), num experimento em casa de vegetação. UFLA, Lavras-MG, 1999

\begin{tabular}{|c|l|l|c|c|c|}
\hline \multirow{2}{*}{ Cobertura } & \multirow{2}{*}{ Posição } & \multicolumn{4}{|c|}{ Taxa de emissão foliar } \\
\cline { 3 - 6 } & & TEF - 01 & TEF - 02 & TEF - 03 & TEF - 04 \\
\hline \multirow{3}{*}{ CC } & DT & $1,15 \mathrm{a}$ & $1,17 \mathrm{a}$ & $1,12 \mathrm{a}$ & $1,07 \mathrm{a}$ \\
& IS & $1,11 \mathrm{ab}$ & $1,15 \mathrm{a}$ & $1,16 \mathrm{a}$ & $1,10 \mathrm{a}$ \\
& IF & $1,08 \mathrm{~b}$ & $1,09 \mathrm{~b}$ & $1,14 \mathrm{a}$ & $1,09 \mathrm{a}$ \\
\hline \multirow{3}{*}{$\mathrm{CA}$} & DT & $1,08 \mathrm{a}$ & $1,09 \mathrm{~b}$ & $1,08 \mathrm{a}$ & $1,04 \mathrm{a}$ \\
& IS & $1,11 \mathrm{a}$ & $1,15 \mathrm{a}$ & $1,09 \mathrm{a}$ & $1,06 \mathrm{a}$ \\
& IF & $1,07 \mathrm{a}$ & $1,14 \mathrm{a}$ & $1,04 \mathrm{a}$ & $1,05 \mathrm{a}$ \\
\hline \multirow{3}{*}{$\mathrm{VE}$} & DT & $1,09 \mathrm{a}$ & $1,11 \mathrm{a}$ & $1,10 \mathrm{a}$ & $1,07 \mathrm{a}$ \\
& IS & $1,06 \mathrm{a}$ & $1,10 \mathrm{a}$ & $1,05 \mathrm{ab}$ & $1,06 \mathrm{a}$ \\
& IF & $1,08 \mathrm{a}$ & $1,03 \mathrm{~b}$ & $1,03 \mathrm{~b}$ & $1,03 \mathrm{a}$ \\
\hline SC & & 1,08 & 1,06 & 1,03 & 1,05 \\
\hline
\end{tabular}

Médias seguidas das mesmas letras, dentro da mesma coluna (por cobertura), não diferem entre si pelo teste de Tukey a $5 \%$ de probabilidade. 
mentos (Tabela 6). Esses valores estão de acordo com aqueles referentes à contagem do número de folhas e, principalmente, coerentes com as alturas das plantas de caruru influenciadas por esses tratamentos.

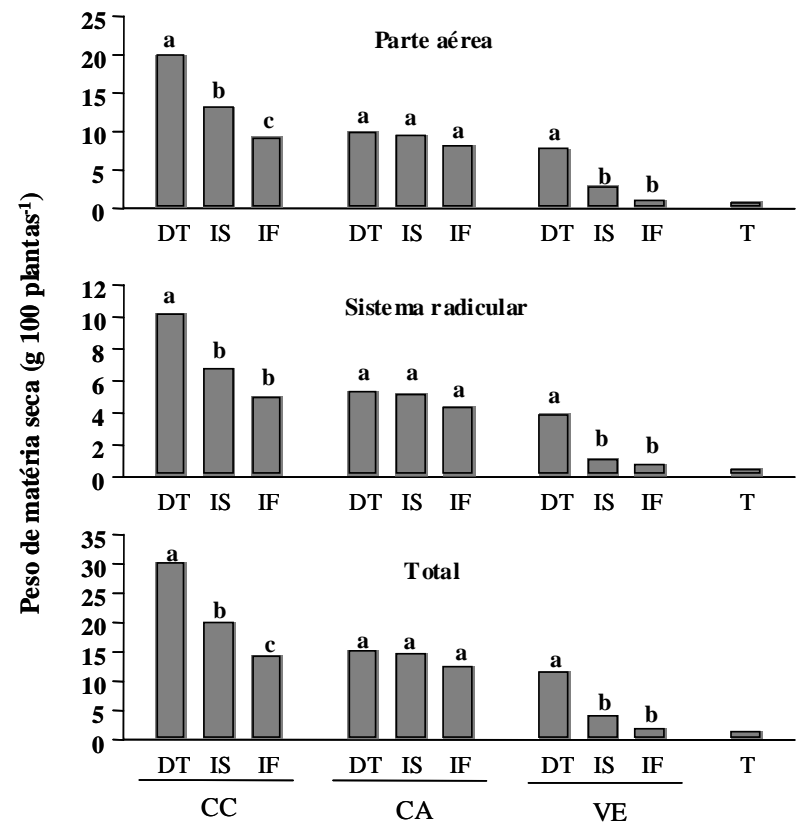

- Médias seguidas das mesmas letras, dentro da mesma coluna (por cobertura), não diferem entre si pelo teste de Tukey a 5\% de probabilidade.

Figura 4 - Peso de matéria seca (g 100 plantas $^{-1}$ ) do carurude-mancha e relação parte aérea/sistema radicular, no final do experimento, aos 43 dias do plantio, correspondentes à aplicação dos tratamentos, em função dos tipos de coberturas mortas de casca de café (CC), casca de arroz (CA) e vermiculita expandida (VE), nas posições depositada no topo (DT), incorporada na superfície (IS) e incorporada no fundo (IF), comparados com os da testemunha sem cobertura $(\mathrm{T})$, num experimento em casa de vegetação. UFLA, Lavras-MG, 1999.

No final do experimento, após determinação do peso da matéria seca da parte aérea e do sistema radicular do caruru-de-mancha, verificou-se que os tipos de coberturas, as formas de disposição e suas interações influenciaram determinantemente o peso da seca do caruru.

Observou-se que a casca de café, seguida da casca de arroz, proporcionou maior incremento da matéria seca tanto na parte aérea como no sistema radicular e da matéria seca total da planta de caruru, comparado aos de- mais tratamentos (Figura 4).

Pode-se visualizar, entre os efeitos de formas de disposição da casca de café, diferenças dos dados de matéria seca em todas as partes e total da planta, com destaque maior para a casca de café depositada no topo, seguida da incorporada na superfície, as quais proporcionaram os maiores valores em relação a todos os tratamentos.

As médias de peso de matéria seca da casca de café depositada no topo foram superiores em torno de $100 \%$ às da casca de arroz em todas as suas formas de disposição no substrato (Tabela 7). As médias da casca de arroz mostraram-se sem diferenças nessas avaliações.

A relação peso da matéria seca parte aérea/ sistema radicular mostrou, para as coberturas de resíduos vegetais, tanto de casca de café como de casca de arroz, valores sem diferenças entre as formas de disposição, apenas havendo variação nos dados pertencentes ao tratamento com vermiculita expandida.

Tabela 7 - Médias do peso da matéria seca (g 100 plantas $\left.^{-1}\right)$ e relação parte aérea/sistema radicular do caruru-de-mancha, no final do experimento, aos 43 dias do plantio, correspondentes à aplicação dos tratamentos das coberturas mortas de casca de café (CC), casca de arroz (CA) e vermiculita expandida (VE), nas posições depositada no topo (DT), incorporada na superfície (IS) e incorporada no fundo (IF), comparadas com as da testemunha sem cobertura (SC), num experimento em casa de vegetação. UFLA, Lavras-MG, 1999

\begin{tabular}{|c|l|r|r|r|c|}
\hline \multirow{2}{*}{ Cobertura } & \multirow{2}{*}{ Posição } & \multicolumn{3}{|c|}{ Peso de matéria seca } & \multirow{2}{*}{ Relação } \\
\cline { 3 - 5 } & & \multicolumn{1}{|c|}{ PA } & \multicolumn{1}{|c|}{ SR } & \multicolumn{1}{c|}{ Total } & PA/SR \\
\hline \multirow{3}{*}{ CC } & DT & $19,99 \mathrm{a}$ & $10,21 \mathrm{a}$ & $30,20 \mathrm{a}$ & $1,97 \mathrm{a}$ \\
& IS & $13,20 \mathrm{~b}$ & $6,78 \mathrm{~b}$ & $19,97 \mathrm{~b}$ & $1,96 \mathrm{a}$ \\
& IF & $9,33 \mathrm{c}$ & $5,05 \mathrm{~b}$ & $14,39 \mathrm{c}$ & $1,79 \mathrm{a}$ \\
\hline \multirow{3}{*}{ CA } & DT & $9,98 \mathrm{a}$ & $5,33 \mathrm{a}$ & $15,31 \mathrm{a}$ & $1,90 \mathrm{a}$ \\
& IS & $9,48 \mathrm{a}$ & $5,26 \mathrm{a}$ & $14,73 \mathrm{a}$ & $1,83 \mathrm{a}$ \\
& IF & $8,10 \mathrm{a}$ & $4,45 \mathrm{a}$ & $12,55 \mathrm{a}$ & $1,84 \mathrm{a}$ \\
\hline \multirow{3}{*}{ VE } & DT & $7,71 \mathrm{a}$ & $3,97 \mathrm{a}$ & $11,68 \mathrm{a}$ & $1,98 \mathrm{~b}$ \\
& IS & $2,92 \mathrm{~b}$ & $1,15 \mathrm{~b}$ & $4,06 \mathrm{~b}$ & $2,67 \mathrm{a}$ \\
& IF & $1,08 \mathrm{~b}$ & $0,80 \mathrm{~b}$ & $1,87 \mathrm{~b}$ & $1,36 \mathrm{c}$ \\
\hline SC & & 0,87 & 0,57 & 1,44 & 1,58 \\
\hline
\end{tabular}

Médias seguidas das mesmas letras, dentro da mesma coluna (por cobertura), não diferem entre si pelo teste de Tukey a $5 \%$ de probabilidade.

PA - parte aérea.

SR - sistema radicular.

Planta Daninha, Viçosa-MG, v.19, n.2, p.197-207, 2001 
Acredita-se, portanto, que o fato de as coberturas de resíduos vegetais propiciarem maiores efeitos no incremento da matéria seca do caruru seja atribuído em grande parte à existência de compostos alelopáticos presentes nesses resíduos, como cafeína na casca de café e fenólicos na casca de arroz, juntamente com possivel fornecimento de nutrientes. Essas substâncias são lixiviadas para o solo durante o processo de degradação, podendo provocar estímulo ao desenvolvimento da planta, porém necessitando de criteriosa análise química para suas determinações específicas.

Quanto à área foliar, verificou-se que os tipos de coberturas mortas, as formas de disposição no substrato e suas interações exerceram influência determinante na dimensão da área foliar do caruru.

As coberturas de resíduos vegetais de casca de café, seguidas da casca de arroz, propiciaram maior desenvolvimento de área foliar do caruru do que os demais tratamentos, com a casca de café depositada no topo, seguida da incorporada na superfície, apresentando os maiores valores (Figura 5). Os resultados referentes às formas de disposição da casca de arroz se mostraram sem diferenças significativas entre si.

Observou-se que a casca de café depositada no topo e aquela incorporada na superfície pro-

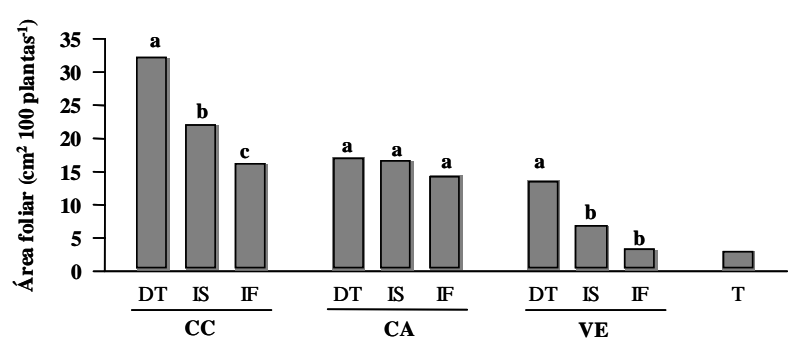

- Médias seguidas das mesmas letras, dentro da mesma cobertura, não diferem entre si pelo teste de Tukey a $5 \%$ de probabilidade.

Figura 5 - Área foliar do caruru-de-mancha $\left(\mathrm{cm}^{2} 100\right.$ plantas $\left.^{-1}\right)$, no final do experimento, aos 43 dias do plantio, correspondente à aplicação dos tratamentos, em função dos tipos de coberturas mortas de casca de café (CC), casca de arroz (CA) e vermiculita expandida (VE), nas posições depositada no topo (DT), incorporada na superfície (IS) e incorporada no fundo (IF), comparadas com a da testemunha sem cobertura (T), num experimento em casa de vegetação. UFLA, Lavras-MG, 1999. porcionaram médias de área foliar, respectivamente, 10,6 e 7,3 vezes maiores do que o tratamento testemunha sem cobertura e 87 e $32 \%$ superiores à da casca de arroz nas mesmas disposições no substrato (Tabela 8).

Os resultados de medição de área foliar do

Tabela 8 - Médias da área foliar do caruru-de-mancha $\left(\mathrm{cm}^{2} /\right.$ 100 plantas), no final do experimento aos 43 dias do plantio, correspondente à aplicação dos tratamentos das coberturas mortas de casca de café (CC), casca de arroz (CA) e vermiculita expandida (VE), nas posições depositada no topo (DT), incorporada na superfície (IS) e incorporada no fundo (IF), comparadas com as da testemunha sem cobertura (SC), num experimento em casa de vegetação. UFLA, Lavras-MG, 1999

\begin{tabular}{|c|l|c|}
\hline \multirow{2}{*}{ Cobertura } & \multirow{2}{*}{ Posição } & Área foliar \\
\cline { 3 - 3 } & & $\left(\mathrm{cm}^{2} 100\right.$ plantas $\left.^{-1}\right)$ \\
\hline \multirow{3}{*}{ CC } & DT & $32,17 \mathrm{a}$ \\
& IS & $21,93 \mathrm{~b}$ \\
& IF & $16,17 \mathrm{c}$ \\
\hline \multirow{3}{*}{ CA } & DT & $17,20 \mathrm{a}$ \\
& IS & $16,56 \mathrm{a}$ \\
& IF & $14,39 \mathrm{a}$ \\
\hline \multirow{2}{*}{ VE } & DT & $13,66 \mathrm{a}$ \\
& IS & $6,73 \mathrm{~b}$ \\
& IF & $3,24 \mathrm{~b}$ \\
\hline SC & & 3,02 \\
\hline
\end{tabular}

Médias seguidas das mesmas letras, dentro da mesma coluna (por cobertura), não diferem entre si pelo teste de Tukey a 5\% de probabilidade.

Tabela 9 - Números de plantas de caruru-de-mancha com sintomas de injúria nos cinco períodos de avaliação, aos 23, 28, 33, 38 e 43 dias do plantio, correspondentes à aplicação dos tratamentos das coberturas mortas de casca de café (CC), casca de arroz (CA) e vermiculita expandida (VE), nas posições depositada no topo (DT), incorporada na superfície (IS) e incorporada no fundo (IF), comparados com os da testemunha sem cobertura (SC), num experimento em casa de vegetação. UFLA, Lavras-MG, 1999

\begin{tabular}{|c|l|c|r|r|r|r|}
\hline \multirow{2}{*}{ Cobertura } & \multirow{2}{*}{ Posição } & \multicolumn{5}{|c|}{ Períodos de avaliações (Dias) } \\
\cline { 3 - 7 } & & 23 & 28 & 33 & 38 & 43 \\
\hline \multirow{3}{*}{ CC } & DT & 4 & 4 & 5 & 6 & 6 \\
& IS & 0 & 0 & 0 & 0 & 0 \\
& IF & 0 & 0 & 0 & 0 & 0 \\
\hline \multirow{3}{*}{ CA } & DT & 9 & 10 & 12 & 13 & 16 \\
& IS & 0 & 0 & 0 & 0 & 0 \\
& IF & 0 & 0 & 0 & 0 & 0 \\
\hline \multirow{3}{*}{ VE } & DT & 0 & 0 & 0 & 0 & 0 \\
& IS & 0 & 0 & 0 & 0 & 0 \\
& IF & 0 & 0 & 0 & 0 & 0 \\
\hline
\end{tabular}


caruru-de-mancha comprovam coerência com os resultados obtidos da matéria seca da parte aérea, indicando existência de possiveis interferências alelopáticas por parte dos resíduos vegetais ou fornecimento de nutrientes, propiciando estímulos para o maior desenvolvimento vegetativo das plantas.

Na avaliação dos sintomas visuais de injúrias apresentados pelo caruru, o número de plantas com clorose foliar, em comparação com a testemunha sem cobertura morta, correspondeu a $80 \%$ para a casca de arroz depositada no topo e $30 \%$ para a casca de café na mesma disposição (Tabela 9).

Os resultados obtidos permitem as seguintes conclusões:

- Os resíduos vegetais de casca de café e casca de arroz, independentemente de sua disposição no substrato, proporcionaram inibição na germinação e estímulo ao crescimento do caruru-de-mancha.

- A casca de arroz, nas três formas de disposição no solo, propicia menores índices de velocidade de emergência e porcentagem de germinação do caruru-de-mancha do que a casca de café.

- A casca de café depositada no topo, seguida daquela incorporada na superfície, proporciona maior estímulo ao crescimento da planta, aumento da área foliar e produção de matéria seca do caruru-de-mancha do que a casca de arroz.

\section{LITERATURA CITADA}

ALMEIDA, F.S. A alelopatia e as plantas. Londrina: IAPAR, 1988. 60p.

ALMEIDA, F.S. Controle de plantas daninhas em plantio direto. Londrina: IAPAR, 1991. 34p.

ARAÚJO, R.C.; SOUZA, R.J.; SILVA, A.M.; ALVARENGA, M.A.R. Efeitos da cobertura morta do solo sobre a cultura do alho (Allium sativum L.). Ci. Prat., v.17, n.3, p.228-233, 1993.

BENINCASA, M.M.P. Análise de crescimento de plantas (Noções Básicas), Jaboticabal: FCAVUNESP, 1988. 41p.
CAMARGO, F.A. O.; SANTOS, G.A.; ROSSIELLO, R.O.P.; ZONTA, E. Incorporação de palha de arroz em um Gleissolo e efeitos no rendimento da cultura de arroz irrigado. Pesq. Agropec. Bras., v.30, n.7, p.983-987, 1995.

DURIGAN, J.C.; ALMEIDA, F.L.S. Noções sobre alelopatia. Jaboticabal: UNESP, 1993. 28p. (Boletim)

FLECK, N.G.; VIDAL, R.A. Efeitos de métodos físicos de controle de plantas daninhas sobre características agronômicas do girassol. Pesq. Agropec. Bras., v.28, n.11, p.1307-1318, 1993.

FRIEDMAN, J. Allelopathy, autotoxicity and germination. In: KIGEL, J.; GALILI, G. Seed development and germination, New York: Marcel Dekker, 1995. p.629-644.

FUERST, E.P.; PUTNAM, A.R. Separating the competitive and allelopathic components of interference theoretical principles. J. Chem. Ecol., v.9, n.8, p.937-944, 1983.

FUJII, Y. The allelopathic effect of some rice varieties. Techn. Bull. Food Fertil. Technol. Center, n.134, p.1-6, 1993.

GALLAGHER, R.S.; CARDINA, J. Phytochromemediated Amaranthus germination I: effect of seed burial and germination temperature. Weed Sci., v.46, p.48-52, 1998.

GOMES, F.P. Curso de estatística experimental. 13.ed. Piracicaba: Nobel, 1990. 468p.

GOMIDE, M.B. Potencialidades alelopáticas dos restos culturais de dois cultivares de canade-açúcar (Saccharum sp.), no controle de algumas plantas daninhas. Piracicaba: ESALQ, 1993. 96p. Tese (Doutorado em Fitotecnia) Escola Superior de Agricultura "Luiz de Queiroz", 1993.

MAGUIRE, J.D. Speed of germination aid in selection and evaluation for seedling emergence and vigor. Crop Sci., v.2, n.1, p.176-177, 1962.

MAZZAFERA, P.; YAMAOKA-YANO, D.M.; VITÓRIA, A.P. Para que serve a cafeína em plantas? R. Bras. de Fis. Veg., v.8, n.1, p.67-74, 1996.

PATRICK, Z.A. Phytotoxic substances associated with the decomposicion in soil of plant residues. Soil Sci., v.3, n.1, p.13-18, 1971.

RICE, E.L. Allelopathy. 2.ed. New York: Academic Press, 1984. 424p.

Planta Daninha, Viçosa-MG, v.19, n.2, p.197-207, 2001 